\title{
CHECKLIST DA FLORA FANEROGÂMICA OCORRENTE NA CAATINGA DE CANUDOS, BAHIA
}

\author{
Andrezza Lóren de Góes Nascimento ${ }^{1}$; Marcos da Costa Dórea²; Hemilly Marques \\ Seixas $^{3}$; Reyjane Patricia de Oliveira ${ }^{4}$ e Francisco de Assis Ribeiro dos Santos ${ }^{5}$ \\ 1. Estagiária Voluntário/PEVIC, Graduanda do Bacharelado em Ciências Biológicas, Universidade Estadual de Feira \\ de Santana, e-mail: andrezzaloren@gmail.com \\ 2. Orientador, Programa de Pós-graduação em Botânica, PNPD/CAPES, Departamento de Ciências Biológicas, \\ Universidade Estadual de Feira de Santana, e-mail: mcdorea@uefs.br \\ 3. Estagiária Voluntário/PEVIC, Graduanda do Bacharelado em Ciências Biológicas, Universidade Estadual de Feira \\ de Santana, e-mail: hemillyseixas@ @otmail.com \\ 4. Departamento de Ciências Biológicas, Universidade Estadual de Feira de Santana, e-mail: rpatricia@uefs.br \\ 5. Departamento de Ciências Biológicas, Universidade Estadual de Feira de Santana, e-mail: fasantos@uefs.br
}

PALAVRAS-CHAVE: florística; Semiárido; Caatinga

\section{INTRODUÇÃO}

O Semiárido brasileiro corresponde basicamente à delimitação do bioma Caatinga e está praticamente incluído no Nordeste do Brasil, juntamente com o norte de Minas Gerais, na região Sudeste, correspondendo a mais de 10\% do território brasileiro (Moura \& Campos 2004).

A Caatinga tem sua flora fanerogâmica estimada em 4.753 espécies (913 endêmicas), 1.226 gêneros e 173 famílias (BFG, 2015; Flora do Brasil 2020). As famílias Fabaceae, Orchidaceae, Asteraceae, Poaceae e Rubiaceae, são consideradas as com maior diversidade nesse bioma (Lewinsohn \& Prado, 2005).

A vegetação do semiárido oferece diversos benefícios ambientais, econômicos e sociais, mas apesar de toda essa importância e dos inventários já realizados na região, muitas áreas ainda são pouco ou completamente desconhecidas do ponto de vista florístico, pelo menos no que diz respeito a certos grupos vegetais (Giulietti \& Queiroz 2006).

Inventários florísticos são de extrema importância para o conhecimento da vegetação local e regional, fornecendo subsídios para outras pesquisas, a exemplo dos estudos palinológicos envolvendo apicultura, meliponicultura e outros voltados para conservação e manejo de polinizadores.

O presente trabalho teve como objetivo principal apresentar um checklist atualizado da flora fanerogâmica ocorrente na caatinga de Canudos, inserida da ecorregião do Raso da Catarina (Velloso et al. 2002), com indicação de espécies endêmicas e apícolas existentes na região.

\section{MATERIAL E MÉTODOS}

A área de estudo foi a Estação Biológica de Canudos (EBC) (0956’40,9”'S e $39^{\circ} 00^{\prime} 55,7^{\prime \prime} \mathrm{W}$ ) e seus arredores, cuja vegetação apresenta-se como uma caatinga hiperxerófita com predominância de elementos arbustivos e outros arbóreos distribuídos esparsamente (Silva et al., 2016). A região apresenta temperatura média anual de 24,15 ${ }^{0} \mathrm{C}$, com os meses mais quentes de novembro a março, que coincide com o período de maior precipitação, geralmente inferior a $400 \mathrm{~mm}$ (SEI, 1998)

Todo o levantamento sobre a caatinga da EBC e seu entorno foi feito através de consulta de coletas realizadas na área através da ferramenta species link. Os dados obtidos foram devidamente triados para uma atualização e correção de nomes com auxílio da plataforma da Flora do Brasil 2020 (http://floradobrasil.jbrj.gov.br) e da base de dados do Missouri Botanical Garden (www.tropicos.org). 
Literatura especializada com informações sobre a vegetação da caatinga foi utilizada para a indicação de endemismos (Giulietti et al., 2002; Silva et al., 2016, Flora do Brasil 2020) e de espécies apícolas (Pereira et al., 2004; Benevides \& Carvalho, 2009; Maia-Silva et al., 2012)

\section{RESULTADOS E DISCUSSÃO}

Os registros de coletas datam de 1944 até 2014, o que representou 1.246 exemplares coletados ao longo desses 70 anos. A maior concentração de coletas foi entre os anos 2000 a 2004, com 1.047 exemplares coletados representando ca. 84\% dos espécimes coletados em todo o período amostrado.

A coleção está distribuída entre 31 herbários, dos quais o Herbário da Universidade Estadual de Feira de Santana (HUEFS) detém a maior coleção com 780 exemplares, $59,5 \%$ do total de coletas realizadas.

A composição florística da EBC foi representada por 357 espécies pertencentes a 225 gêneros e 71 famílias (Figura 1). As famílias com maior diversidade foram Fabaceae (79 spp.), Euphorbiaceae (48 spp.), Malpighiceae (30 spp.), Bignoniaceae (29 spp.), Poaceae (24 spp.), Malvaceae (22 spp.), Asteraceae (20 spp.), Convolvulaceae (18 spp.), Rubiaceae (15 spp.), Verbenaceae (13 spp.) e Cactaceae (12 spp.).

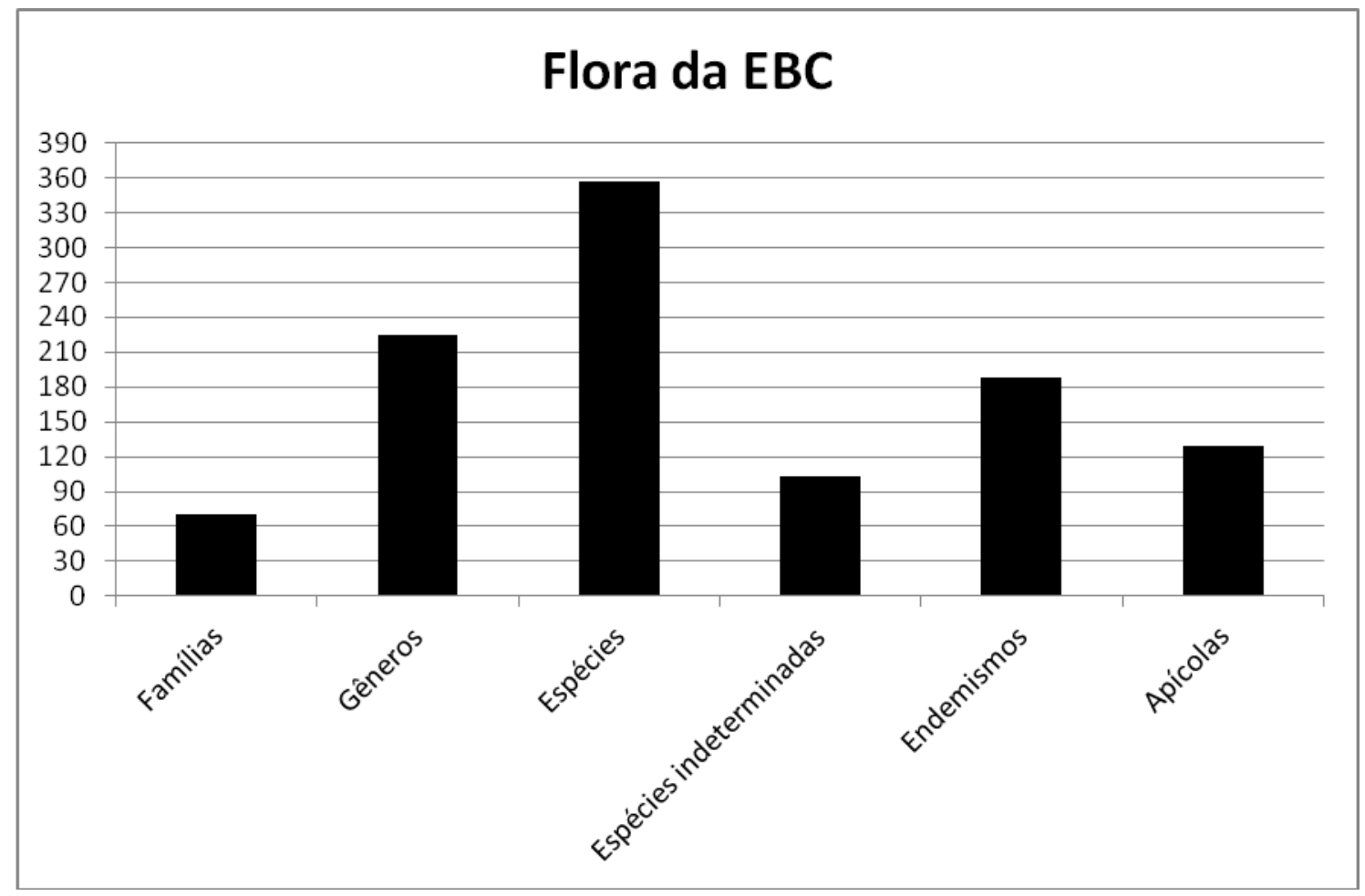

Figura 1. Dados da flora fanerogâmica da Estação Biológica de Canudos, Canudos, Bahia.

Das 913 espécies consideradas endêmicas da Caatinga (BFG, 2015), 188 foram registradas para Canudos, representando ca. 20,5\% das espécies e demonstrando um elevado grau de endemismos para a vegetação local.

Entre as espécies levantadas, 129 são consideradas apícolas de acordo com a literatura consultada (Nunes et al., 1996; Pereira et al., 2004; Rodarte et al., 2008; Benevides \& Carvalho, 2009; Maia-Silva et al., 2012; Silva, 2014). Esse número elevado de espécies aponta o quanto a flora das caatingas tem um importante potencial para $o$ desenvolvimento das atividades de apicultura e meliponicultura. 


\section{CONSIDERAÇÕES FINAIS}

Os dados da flora de Canudos demonstram que a região apresenta uma grande diversidade florística, com importante número de endemismos e potencial para atividades apícolas/meliponícolas.

A compilação dessas informações é de grande importância para subsidiar com dados vários estudos no âmbito da botânica. Um exemplo disso tem-se a publicação da Flora Polínica das Caatingas (Silva et al., 2016), desenvolvida exclusivamente com as plantas encontradas na EBC e configurando uma das poucas e importantes publicações sobre a palinologia da Caatinga.

O checklist acaba sendo o primeiro e importante passo, após as coletas, para dar uma noção do estado da diversidade florística local e a partir daí serem iniciadas tomadas de decisões a cerca de planos de manejo e conservação da flora e fauna associadas, entre outros estudos que dependem do conhecimento prévio da vegetação local.

\section{REFERÊNCIAS}

BFG - The Brazil Flora Group (2015) Growing knowledge: an overview of Seed Plant diversity in Brazil. Rodriguésia 66(4):1085-1113

BENEVIDES, D.S.; CARVALHO, F.G. 2009. Levantamento da flora apícola presente em áreas de caatinga do município de Caraúbas - RN. Natal: Sociedade e Território, v. 21, nº 1 - 2 (Edição Especial), p. 44 - 54, jan./dez. 2009.

FLORA DO BRASIL 2020 em construção. Jardim Botânico do Rio de Janeiro. Disponível em: <http://floradobrasil.jbrj.gov.br/ >. Acesso em: 05 Ago. 2017

GIULIETTI, A.M. et al. 2002. Espécies endêmicas da Caatinga. In: E.V.C.B. Sampaio et al. (Eds.) Vegetação \& Flora da Caatinga. Associação Plantas do Nordeste, CNIP, Recife.

GIULIETTI, A.M.; QUEIROZ, L.P. (Org.). 2006. Instituto do Milênio do Semi-árido. 1. ed. Recife: APNE, 2000p.

LEWINSOHN, T.M.; PRADO, P.I. 2005. How many species are ther in Brazil. Conservation Biology 19(3): 701-706.

MAIA-SILVA, C. et al. 2012. Guia de plantas visitadas por abelhas na Caatinga. 1. Ed. Editora Fundação Brasil Cidadão, Fortaleza, CE.

MOURA, A.S.; CAMPOS, G.C. (coord.) 2004. Cenários para o bioma Caatinga. Conselho Nacional da Reserva da Biosfera da Caatinga, Secretaria da Ciência, Tecnologia e Meio Ambiente de Pernambuco, Recife.

NUNES, C.G.F. et al. 1996. IDENTIFICAÇÃO DE PLANTAS APÍCOLAS NO CAMPUS DA ESAM, MOSSORÓ-RN. Monografia. Mossoró-RN, 9(1/2): 91-96.

PEREIRA, F.M. et al. 2004. Flora apícola no Nordeste. Embrapa Meio-Norte, 21 ed. 40 p. Teresina - PI.

RODARTE, A.T.A.; SILVA, F.O.; VIANA, B. F. 2008. A flora melitófila de uma área de dunas com vegetação de caatinga, Estado da Bahia, Nordeste do Brasil. Acta Bot. Bras. [online]. vol.22, n.2, pp.301-312. ISSN 0102-3306.

SEI. 1998. Atributos climáticos do Estado da Bahia. Série Estudos e Pesquisas, v.38. Secretaria de Planejamento Ciências e tecnologia do Estado da Bahia, Salvador.

SILVA, J.I. 2014. Diversidade da flora apícola no município de São João do Piauí. 61f. Dissertação - Universidade Federal do Piauí. Teresina.

SILVA, F.H.M.; SANTOS, F.A.R.; LIMA, L.C.L. 2016. Flora polínica das caatingas: Estação Biológica de Canudos (Canudos, Bahia, Brasil). Feira de Santana, Micron Bahia, 120p.

VELLOSO, A.; SAMPAIO, E.V.S.B.; PAREYN, F. G. C. 2002. Ecorregiões: propostas para o bioma caatinga. Recife, Associação Plantas do Nordeste \& Instituto de Conservação Ambiental The Nature Conservancy do Brasil. 